\title{
Clinical study of radiofrequency ablation combined with TACE in the treatment of breast cancer with liver metastasis
}

\author{
HAIJUN WANG ${ }^{1}$, BIN LIU ${ }^{2}$, HOULONG LONG ${ }^{2}$, FENGFENG ZHANG ${ }^{2}$, SILEI WANG ${ }^{2}$ and FENG LI $^{2}$ \\ ${ }^{1}$ Department of General Surgery, Anqiu Hospital of Chinese Traditional Medicine, Anqiu, Shandong 262100; \\ ${ }^{2}$ Department of Thyroid and Breast Surgery, Tengzhou Central People's Hospital, Tengzhou, Shandong 277500, P.R. China
}

Received February 2, 2017; Accepted May 5, 2017

DOI: $10.3892 / 01.2017 .6483$

\begin{abstract}
We studied the clinical effects of percutaneous radiofrequency ablation (RFCA) combined with transcatheter arterial chemoembolization (TACE) in the treatment of breast cancer with liver metastasis. Eighty-eight patients with a diagnosis of breast cancer with liver metastasis for the first time and patients with liver metastasis after radical mastectomy were consecutively selected. The subjects were divided according to the different treatment methods. They were divided either into the control group of 50 cases or the observation group of 38 cases. Breast cancer patients underwent radical mastectomy with conventional systemic venous chemotherapy. The liver metastasis control group used TACE, while the observation group combined RFCA with TACE. The two groups were followed up for a median time of 20 months, and the clinical effects were compared. The effective rate of the observation group was higher than that of the control group; differences were statistically significant $(\mathrm{P}<0.05)$. There was no differences in the incidence of complications between the two groups $(\mathrm{P}>0.05)$. The progression free survival, median survival time and survival rate of the observation group were increased; differences were statistically significant $(\mathrm{P}<0.05)$. Therefore, RFCA combined with TACE in the treatment of breast cancer with liver metastasis is safe and effective.
\end{abstract}

\section{Introduction}

Breast cancer incidence rate ranks first in female malignant tumors. Liver metastasis in breast cancer is third only to lung and bone metastasis. The breast cancer liver metastasis rate is $\sim 55.0-75.0 \%$. In $\sim 5.0-45.0 \%$ of patients, liver is the only metastatic site (1). The overall median survival

Correspondence to: Dr Feng Li, Department of Thyroid and Breast Surgery, Tengzhou Central People's Hospital, 181 Xingtan Road, Tengzhou, Shandong 277500, P.R. China

E-mail: lifenghh1972@163.com

Key words: percutaneous radiofrequency ablation, transcatheter arterial chemoembolization, breast cancer, liver metastasis period of patients with liver metastasis due to breast cancer is $\sim 14$ months. Approximately $20.0-45.0 \%$ of patients with breast cancer 5 years after radical resection have distant metastases, and $6.0-40.0 \%$ of patients have distant metastases at the time of initial diagnosis (2). The main treatments for breast cancer with liver metastasis are surgical resection, transcatheter arterial chemoembolization (TACE), percutaneous radiofrequency ablation (RFCA), ethanol injection, and microwave ablation $(3,4)$. The safety and effectiveness of TACE and RFCA in primary hepatocellular carcinoma have been confirmed $(5,6)$, however, due to the different molecular biological characteristics of metastatic liver cancer, there is no uniform understanding regarding whether RFCA and TACE are equally effective at present. The previous study conducted on this subject had a much lower sample size, with a lack of comparative analysis. Based on previous results, this study attempts to explain the clinical effects of both TACE and RFCA in the treatment of breast cancer with liver metastasis.

\section{Materials and methods}

Sample selection. Eighty-eight patients with a diagnosis of breast cancer with liver metastasis at Tengzhou Central People's Hospital from January 2013 to January 2016 were consecutively selected. The inclusion criteria were as follows. i) Age $\leq 70$. ii) Diagnosis of breast cancer with liver metastasis, or breast cancer after radical surgery with liver metastasis, confirmed by pathology. This study was approved by the Ethics Committee of Tengzhou Central People's Hospital. Signed written informed consents were obtained from all participants before the study. iii) No presence of extrahepatic metastasis and liver metastases were diagnosed by ultrasound, MRI or $\mathrm{CT}$, without any surgical resection indications, with TACE and RFCA application indications. iv) The KPS score $\geq 70$, and ECOG $<2$, after liver function was corrected in the normal range, there was a tolerance to the risk of treatment of TACE and RFCA. v) The clinical data were perfect and the informed consent was obtained. The exclusion criteria were: i) breast cancer chemotherapy response was poor, the condition was serious, and the survival was expected to be $<12$ months. ii) There were serious underlying diseases, such as heart, lung, brain, kidney and other organs dysfunction, and other parts of the primary malignant tumors. 
Table I. Comparison of therapeutic effects of two groups of metastatic lesions [case (\%)].

\begin{tabular}{lcccccc}
\hline Group & No. of cases & CR & PR & SD & PD & Effective rate \\
\hline Control group & 50 & 5 & 27 & 10 & 8 & $32(64.0)$ \\
Observation group & 38 & 10 & 22 & 3 & 3 & $32(84.2)$ \\
$\chi^{2}$ test & & & & & & 4.446 \\
P-value & & & & & & 0.035
\end{tabular}

Table II. Comparison of complications [case (\%)].

\begin{tabular}{lcccccc}
\hline Group & $\begin{array}{c}\text { No. of } \\
\text { cases }\end{array}$ & $\begin{array}{c}\text { Bone marrow } \\
\text { suppression }\end{array}$ & Infected & $\begin{array}{c}\text { Severe digestive } \\
\text { tract symptoms }\end{array}$ & $\begin{array}{c}\text { Liver and } \\
\text { kidney damage }\end{array}$ & $\begin{array}{c}\text { Other } \\
\text { Complication } \\
\text { rate }\end{array}$ \\
\hline $\begin{array}{l}\text { Control group } \\
\text { Observation group }\end{array}$ & 50 & 1 & 1 & 2 & 1 & 1 \\
$\begin{array}{l}\chi^{2} \text { test } \\
\text { P-value }\end{array}$ & & 1 & 1 & 1 & 1 & 0 \\
\end{tabular}

Table III. Comparison of progression-free survival, median survival time and survival rate.

\begin{tabular}{lcccc}
\hline Group & No. of cases & Progression-free survival & Median survival time & Survival rate \\
\hline Control group & 50 & 5.7 & 11.9 & $25(50.0)$ \\
Observation group & 38 & 8.2 & 15.6 & $27(71.1)$ \\
$\chi^{2}$ test & & 5.967 & 6.324 & 3.959 \\
P-value & & 0.008 & 0.003 & 0.047 \\
\hline
\end{tabular}

According to the different treatment methods, the patients were divided into two groups of controls of 50 cases and the observation group of 38 cases. The average age of the control group was $56.7 \pm 14.5$ years. The diagnosis of breast cancer with liver metastasis was present in 32 cases, and breast cancer after radical surgery with liver metastasis was present in 18 cases. The average diameter of breast cancer was $3.8 \pm 1.4 \mathrm{~cm}$, the average number was $1.5 \pm 0.6$, the average number of metastatic lymph nodes was $6.5 \pm 2.3$ with the pathological type of invasive ductal carcinoma in 32 cases. There were 15 cases of small leaf cancer, and 3 other cases. There was an average of $6.2 \pm 2.5$ months after radical operation with a presence of hepatic metastases. The average metastasis was $1.3 \pm 0.4$, with an average maximum diameter of $3.3 \pm 1.2$. The mean serum AFP was $685.7 \pm 124.6 \mu \mathrm{g} / \mathrm{l}$. The average age of the observation group was $58.2 \pm 13.6$ years, with the first diagnosis of breast cancer with liver metastasis in 30 cases. Breast cancer after radical surgery with liver metastasis was in 8 cases. The average diameter of breast cancer was $4.1 \pm 1.7 \mathrm{~cm}$, the average number was $1.4 \pm 0.5$, the average number of metastatic lymph nodes was $6.3 \pm 2.2$, with a pathological type of invasive ductal carcinoma in 25 cases, 11 cases of small leaf cancer, and 2 other cases. There was an average of $5.8 \pm 2.1$ months after the radical operation to hepatic metastases. The average metastasis was $1.2 \pm 0.3$, average max diameter was $3.5 \pm 1.3$, and the mean serum AFP was $724.5 \pm 133.8 \mu \mathrm{g} / 1$. The baseline data in both groups were comparable.
Research methods. Breast cancer patients underwent radical mastectomy with conventional systemic venous chemotherapy. The liver metastasis control group used TACE, while the observation group combined RFCA with TACE. The intravenous chemotherapy administered was epirubicin + cyclophosphamide sequential docetaxel + trastuzumab (EC-TH) or epirubicin + cyclophosphamide followed by paclitaxel + trastuzumab (EC-PH). The TACE scheme is Changchun vinorelbine + capecitabine (NX) with or without trastuzumab $(\mathrm{H})$, docetaxel + capecitabine $(\mathrm{TX})$ with or without trastuzumab $(\mathrm{H})$. The Seldinger method was successfully used to insert into the right femoral artery, and the catheter was selectively inserted into the hepatic artery of the celiac artery, which was injected into the hepatic artery. The tumor location, size and distribution of the blood supply were established. This was conducted according to the appropriate dose of drug injections, combined with embolization materials (Yangze Pharm, Taizhou, China). We used the Radionics radiofrequency treatment instrument and the Cool-tip radiofrequency ablation electrode needle (Johnson \& Johnson, New York, NY, USA), with the exposed end of $3 \mathrm{~cm}$. The ultrasound guided percutaneous ablation was inserted into the appropriate depth of the tumor with a adjustment to the maximum power. The single ablation was $10 \mathrm{~min}$, multi-point ablation; by edge needle ablation methods, the ablation range completely covered the tumor to the edge of $0.5-1.0 \mathrm{~cm}$. In the operation, the surgeon judged whether full ablation was completely achieved. One, 
3, 6, 9 and 12 months after operation, the ultrasound, CT or MRI were performed to assess the progression and recurrence of metastatic lesions. During treatment, the condition changes were closely monitored, and the serious adverse drug reactions were observed with symptomatic treatment.

Observation index. The two groups were followed up for 6.0-35.0 months, and the median time was 20 months. The treatment effects, complications, progression-free survival, median survival and survival rate of the two groups were compared. According to the RECIST evaluation criteria in solid tumors, the lesions disappeared in complete remission (CR). The sum of lesion length diameter decreased $\geq 30 \%$, and was maintained at least 1 month for partial remission (PR). The total length and diameter of lesion decreased $<30 \%$ or increases $<30 \%$. There were no new lesions found to be stable (SD), otherwise progress $(\mathrm{PD})$. Effective $=(\mathrm{CR}+\mathrm{PR}) /$ total number of cases $\times 100 \%$.

Statistical analysis. The statistical analysis was performed by SPSS 20.0 software (IBM, Armonk, NY, USA). The measurement data were expressed as mean \pm standard deviation. An independent sample t-test was used in the comparison between groups. The count data was expressed as a number of cases or $(\%)$. The comparison between groups was tested by $\chi^{2}$. Survival was analyzed by the Kaplan-Meier model and log-rank $\chi^{2}$ test. $\mathrm{P}<0.05$ indicated that the difference was statistically significant.

\section{Results}

Comparison of therapeutic effects of two groups of metastatic lesions. The effective rate of the observation group was higher than that of the control group, and the difference was statistically significant $(\mathrm{P}<0.05)$ (Table I).

Comparison of complications. There were no differences in the incidence of complications between the two groups ( $\mathrm{P}>0.05)$ (Table II).

Comparison of progression-free survival, median survival time and survival rate. The progression free survival, median survival time and survival rate of the observation group were increased; differences were statistically significant $(\mathrm{P}<0.05)$ (Table III).

\section{Discussion}

It has been found that the primary tumors with a diameter $>2 \mathrm{~cm}$ can release $\sim 3-4 \times 10^{6} / \mathrm{g}$ tumor cells per day into the blood circulation (7). Endothelial cells of the hepatic blood sinus lack the basement membrane and membrane, with $0.1 \mu \mathrm{m}$ small holes. The liver blood volume is larger, the flow rate is slow and there is a lack of the necessary barriers to the transfer of cells. This causes the liver to be the place where bodies malignant tumors are easy to move (8). At the same time, cancer cells can stimulate the secretion of a variety of cytokines, including vascular endothelial growth factor, hepatocyte growth factor (9), and extracellular matrix components (10). This provides a powerful condition to the proliferation of the metastatic lesions.
Systemic chemotherapy is the standard treatment for breast cancer liver metastasis, but the liver of the drug uptake rate is up to $>95 \%$, with a significant first pass effect; the overall effective rate is only $30-55 \%$ (11). Due to poor general condition, multiple metastases, deep location, and closeness to the large blood vessels and so on, surgical resection is restricted (12). DSA hepatic artery angiography showed that most of the metastatic liver cancer showed a rich blood supply. Although most of the liver metastases transfer from portal vein, most of the blood supply is from the hepatic artery (13). TACE can increase the local concentration of chemotherapeutic drugs and reduce the side effects of systemic chemotherapy (14). They can combine iodine oil and gelatin sponge with an embolization of tumor blood vessels which control the slow release of chemotherapy drugs. Therefore, the tumor tissue will have hypoxia, necrosis and apoptosis (15). The median survival period will increase at least 5.0-8.0 months (16). As an important embolization agent, liquefied petroleum can be retained in the tumor tissue for a long time, a few months or even $>1$ year; the normal liver tissue can disappear after a few days. This feature is on the basis for the treatment of malignant liver tumors (17). TACE can significantly reduce the tumor size, and increase the chances of surgical resection (18). Good results can be achieved in patients with tumor thrombus in the portal vein or hepatic vein (19).

RFCA uses a high frequency electromagnetic wave ion shock to create heat, and therefore, the central temperature of the tumor reaches $>60^{\circ} \mathrm{C}$. This causes the vascular occlusion and coagulation necrosis, resulting in killing of the tumor (20). Ultrasound guidance has advantages of real-time monitoring, accurate guidance, less trauma, safety and effectiveness, simple operation and repeatability (21). RFCA has a good application value in local liver cancer and renal cell carcinoma $(22,23)$. The deficiency is that RFCA has the function of 'heat sink' and 'three dimensional leakage effect', which is not ideal in the tumors of large diameter and special locations (such as large blood vessel, diaphragm, gallbladder, heart and some other parts) (24). At the same time, the combination of RFCA and TACE can exert complementary advantages, and improve the effects of tumor treatment $(25,26)$.

The results have shown that the effective rate of the observation group are higher than that of the control group. The progression-free survival and median survival time were prolonged, and the survival rate was improved. There were no differences in the incidence of complications. Results suggest that RFCA combined with TACE in the treatment of breast cancer with liver metastasis is safe and effective, and has good application value. Therefore, by increasing the sample size, extending the follow-up time, and controlling the influencing factors, these results can be further verified.

\section{References}

1. Yung KW, Yung TT, Chung CY, Tong GT, Liu Y, Henderson J, Welbeck D and Oseni S: Principles of cancer staging. Asian Pac J Surg Oncol 1: 1-16, 2015.

2. Ghoneum M, Felo N, Nwaogu OM, Fayanju IY, Jeffe JA and Margenthaler DB: Clinical trials in Surgical Oncology. Asian Pac J Surg Oncol 1: 73-82, 2015.

3. Mellotte G, Maher V, Devitt PG, Shin VY and Leung CP: Minimally invasive Surgical Oncology: State of the art. Asian Pac J Surg Oncol 1: 101-112, 2015. 
4. Guarneri A, Franco P, Trino E, Campion D, Faletti R, Mirabella S, Gaia S, Ragona R, Diotallevi M, Saracco G, et al: Stereotactic ablative radiotherapy in the treatment of hepatocellular carcinoma >3 cm. Med Oncol 33: 104, 2016.

5. Ippolito D, Trattenero C, Talei FranzesiC, Casiraghi A,Lombardi S, Vacirca F, Corso R and Sironi S: Dynamic contrast-enhanced magnetic resonance imaging with gadolinium ethoxybenzy diethylenetriamine pentaacetic acid for quantitative assessment of vascular effects on hepatocellular-carcinoma lesions treated by transarterial chemoembolization or radiofrequency ablation. J Comput Assist Tomogr 40: 692-700, 2016.

6. Chen R, Gan Y, Ge N, Chen Y, Wang Y, Zhang B, Wang Y, Ye S and Ren Z: Transarterial chemoembolization versus radiofrequency ablation for recurrent hepatocellular carcinoma after resection within barcelona clinic liver cancer stage $0 / \mathrm{A}$ : A retrospective comparative study. J Vasc Interv Radiol 27: 1829-1836, 2016.

7. Spolverato G, Vitale A, Bagante F, Connolly R and Pawlik TM: Liver resection for breast cancer liver metastases: A cost-utility analysis. Ann Surg 265: 792-799, 2017.

8. Sadot E, Lee SY, Sofocleous CT, Solomon SB, Gönen M, Peter Kingham T, Allen PJ, DeMatteo RP, Jarnagin WR, Hudis CA, et al: Hepatic resection or ablation for isolated breast cancer liver metastasis: A case-control study with comparison to medically treated patients. Ann Surg 264: 147-154, 2016.

9. Chen J, Lai L, Liu S, Zhou C, Wu C, Huang M and Lin Q: Targeting HIF- $1 \alpha$ and VEGF by lentivirus-mediated RNA interference reduces liver tumor cells migration and invasion under hypoxic conditions. Neoplasma 63: 934-940, 2016.

10. Ma R, Feng Y, Lin S, Chen J, Lin H, Liang X, Zheng H and Cai X: Mechanisms involved in breast cancer liver metastasis. J Transl Med 13: 64, 2015.

11. Lee R, Yeung AW, Hong SE, Brose MS and Michels DL: Principles of medical oncology. Asian Pac J Surg Oncol 1: 39-46, 2015.

12. Zheng YF, Tan LK, Tan BH, Sterling H and Kane R: Principles of surgical oncology. Asian Pac J Surg Oncol 1: 17-26, 2015.

13. Dai WC and Cheung TT: Strategic overview on the best treatment option for intrahepaitc hepatocellular carcinoma recurrence. Expert Rev Anticancer Ther 16: 1063-1072, 2016.

14. Pecorelli A, Lenzi B, Gramenzi A, Garuti F, Farinati F, Giannini EG, Ciccarese F, Piscaglia F, Rapaccini GL, Di Marco M, et al: Italian Liver Cancer (ITA.LI.CA) group. Curative therapies are superior to standard of care (transarterial chemoembolization) for intermediate stage hepatocellular carcinoma. Liver Int: Aug 27, 2016 (Epub ahead of print). doi: 10.1111/liv.13242.

15. Wan X, Zhai X, Yan Z, Yang P, Li J, Wu D, Wang K, Xia Y and Shen F: Retrospective analysis of transarterial chemoembolization and sorafenib in Chinese patients with unresectable and recurrent hepatocellular carcinoma. Oncotarget 7: 83806-83816, 2016.
16. Ludwig JM, Zhang D, Xing M and Kim HS: Meta-analysis: adjusted indirect comparison of drug-eluting bead transarterial chemoembolization versus ${ }^{90} \mathrm{Y}$-radioembolization for hepatocellular carcinoma. Eur Radiol: Aug 25, 2016 (Epub ahead of print).

17. Choi JW, Kim HC, Lee JH, Yu SJ, Kim YJ, Yoon JH, Jae HJ, Hur S, Lee M and Chung JW: Transarterial chemoembolization of hepatocellular carcinoma with segmental portal vein tumour thrombus. Eur Radiol: Aug 11, 2016 (Epub ahead of print).

18. Hou YF, Wei YG, Yang JY, Wen TF, Xu MQ, Yan LN and Li B: Combined hepatectomy and radiofrequency ablation versus TACE in improving survival of patients with unresectable BCLC stage B HCC. Hepatobiliary Pancreat Dis Int 15: 378-385, 2016.

19. Ha Y, Lee D, Shim JH, Lim YS, Lee HC, Chung YH, Lee YS, Park SR, Ryu MH, Ryoo BY, et al: Role of transarterial chemoembolization in relation with sorafenib for patients with advanced hepatocellular carcinoma. Oncotarget 7: 74303-74313, 2016.

20. Cahill T, Chen XL, Lee JW, Weiss M, Chang VT and Cella D: Principles of radiofrequency ablation for cancer. Asian Pac J Surg Oncol 1: 47-58, 2015.

21. Wu J, Lin S, Wu W, Yan K, Dai Q and Chen M: Clinical application of ultrasound-guided radiofrequency ablation for primary hepatocellular carcinoma near the liver surface. Zhonghua Zhong Liu Za Zhi 37: 933-937, 2015 (In Chinese).

22. Nitta H, Nakagawa S, Kaida T, Arima K, Higashi T, Taki K, Okabe H, Hayashi H, Hashimoto D, Chikamoto A, et al: Pre-treatment double- or triple-positive tumor markers are predictive of a poor outcome for patients undergoing radiofrequency ablation for hepatocellular carcinoma. Surg Today 47: 375-384, 2017.

23. Xu L, Rong Y, Wang W, Lian H, Gan W, Yan X, Li X and Guo H: Percutaneous radiofrequency ablation with contrast-enhanced ultrasonography for solitary and sporadic renal cell carcinoma in patients with autosomal dominant polycystic kidney disease. World J Surg Oncol 14: 193, 2016.

24. Seror O, N' Kontchou G, Nault JC, Rabahi Y, Nahon P, Ganne-Carrié N, Grando V, Zentar N, Beaugrand M, Trinchet JC, et al: Hepatocellular carcinoma within milan criteria: No-touch multibipolar radiofrequency ablation for treatment-long-term results. Radiology 280: 981, 2016.

25. Tang C, Shen J, Feng W, Bao Y, Dong X, Dai Y, Zheng Y and Zhang J: Combination therapy of radiofrequency ablation and transarterial chemoembolization for unresectable hepatocellular carcinoma: A retrospective study. Medicine (Baltimore) 95: e3754, 2016.

26. Shi F, Zhang L, Li S, Lin CJ, Shen LJ, Li CF, Jie M, Li ZW and Wu PH: Chemolipiodolization with or without embolization in transcatheter arterial chemoembolization combined with radiofrequency ablation for hepatocellular carcinoma-propensity score matching analysis. Oncotarget 7: 31311-31321, 2016. 